\title{
Absorption of phenol red from the human lung
}

\author{
J. L . M A D D O C K S ${ }^{1}$ \\ Department of Bacteriology, Institute of Diseases of the Chest, Brompton, London
}

\begin{abstract}
Maddocks, J. L. (1975). Thorax, 30, 333-336. Absorption of phenol red from the human lung. Pulmonary absorption of phenol red was studied in normal subjects. Phenol red was administered by intratracheal injection and its urinary excretion was used as an index of pulmonary absorption.

Doses ranging from 3 to $30 \mathrm{mg}$ were given to two subjects and urinary phenol red excretion was found to be rate limited. That this effect occurred in the lung was shown by giving the dye intravenously to one subject. A linear relationship between dose and urinary excretion was then observed.

Intratracheal p-aminohippurate did not reduce pulmonary absorption of phenol red in one subject.

Pulmonary absorption of phenol red dissolved in $0.9 \%$ saline and in $0.18 \%$ saline was compared in nine subjects. Dye absorption was three times greater when it was given in $0.18 \%$ saline.

When the saline concentration of phenol red doses was held constant there was a linear relationship between the intratracheal dose and urinary excretion in one subject.

These results suggest that phenol red is absorbed from the lung by passive diffusion. They also show the importance of solvent effects when studying pulmonary absorption of a substance.
\end{abstract}

Little is known of the quantitative aspects of pulmonary absorption of drugs in man (Schanker, 1972). In this study phenol red (PSP) was used to study pulmonary absorption as it is non-toxic, non-irritant to the lungs, and is rapidly eliminated in the urine (Abramson et al., 1949). Phenol red was administered by intratracheal injection and its urinary excretion was used as an index of pulmonary absorption.

\section{SUBJECTS AND METHODS}

Nine healthy subjects (5 males, 4 females) were studied. Their ages ranged from 19 to 33 (mean 26) years. Informed consent was obtained from each subject.

Intratracheal injection was performed with the subject seated in a chair with the chest tilted at $15^{\circ}$ to the vertical so that dye injected into the trachea would pass down the right bronchus. Skin over the cricothyroid membrane was then infiltrated with $2 \%$ lignocaine. After a few minutes $2 \mathrm{ml}$ of $2 \%$ lignocaine was injected into the

${ }^{1}$ Present address: KRUF Institute of Renal Disease, Royal Infirmary, Cardiff trachea through the cricothyroid membrane. This was followed by vigorous coughing and resulted in numbing of the throat and some loss of voice. A few minutes later a further $2 \mathrm{ml}$ of $2 \%$ lignocaine was injected into the trachea to test for abolition of the cough reflex. When this had occurred PSP solution was injected into the trachea.

Phenol red, phenolsulphonphthalein injection, USP (Hynson, Westcott and Dunning, Inc., Baltimore) containing $6 \mathrm{mg} / \mathrm{ml}$ in sterile $0.9 \%$ saline was used in these studies. Each dose of phenol red solution was made up to $5 \mathrm{ml}$ with sterile water or $0.9 \%$ saline. Intratracheal injections were performed at weekly intervals.

Before receiving an intratracheal injection of PSP each subject passed urine and drank $500 \mathrm{ml}$ of water to ensure that urine could be passed during the experiment. All urine passed by each subject $0.5,1,2$, and 3 hours after the intratracheal injection was collected and its volume measured.

PSP was assayed spectrophotometrically at $560 \mathrm{~nm}$ after the addition of $5 \mathrm{~N}$ sodium hydroxide ( $1 \mathrm{ml}$ per $100 \mathrm{ml}$ of urine) and filtration. Control urine collections from each subject were used for 
blank readings. Recovery of PSP added to urine was complete.

\section{RESULTS}

INTRATRACHEAL DOSE OF PSP AND ITS URINARY EXCRETION The relationship between the intratracheal dose and urinary excretion of PSP was studied in subjects J.M. and D.G. Each dose was prepared from PSP solution $(6 \mathrm{mg}$ per $\mathrm{ml}$ in $0.9 \%$ saline) and its volume was made up to $5 \mathrm{ml}$ with water. Saline concentrations of the doses were therefore variable and were lowest in the smallest doses. The results are shown in Table I. Although there was a tenfold range of dosage, the urinary excretion of PSP in the first hour after injection of doses ranging from 3 to $18 \mathrm{mg}$ was fairly constant $(1 \cdot 1-1 \cdot 3 \mathrm{mg})$ and only a little higher (mean $=1.8 \mathrm{mg}$ ) after the $30 \mathrm{mg}$ dose. There was thus evidence of rate limitation of PSP excretion after intratracheal administration.

T A B L E I

CUMULATIVE WEIGHT (mg) OF PSP EXCRETED IN THE URINE OF TWO SUBJECTS AFTER VARIOUS INTRATRACHEAL DOSES

\begin{tabular}{|c|c|c|c|c|c|c|}
\hline \multirow{3}{*}{$\begin{array}{c}\text { Intratracheal } \\
\text { Dose (mg) }\end{array}$} & \multicolumn{6}{|c|}{ Cumulative Weight $(\mathrm{mg})$ of PSP in Urine } \\
\hline & \multicolumn{2}{|c|}{$1 \mathrm{hr}$} & \multicolumn{2}{|c|}{$2 \mathrm{hr}$} & \multicolumn{2}{|c|}{$3 \mathrm{hr}$} \\
\hline & J.M. & D.G. & J.M. & D.G. & J.M. & D.G. \\
\hline $\begin{array}{r}3 \cdot 0 \\
6 \cdot 0 \\
7 \cdot 2 \\
12 \cdot 0 \\
18 \cdot 0 \\
30 \cdot 0\end{array}$ & $\begin{array}{l}1 \cdot 1 \\
1 \cdot 3 \\
1 \cdot 1 \\
1 \cdot 2 \\
1 \cdot 6\end{array}$ & $\begin{array}{l}\overline{1 \cdot 1} \\
\overline{1 \cdot 1} \\
1 \cdot 1 \\
2 \cdot 0\end{array}$ & $\begin{array}{l}1 \cdot 5 \\
2 \cdot 2 \\
2 \cdot 2 \\
2 \cdot 4 \\
3 \cdot 7\end{array}$ & $\begin{array}{l}\overline{1 \cdot 6} \\
\frac{2 \cdot 6}{4 \cdot 1}\end{array}$ & $\begin{array}{l}1 \cdot 8 \\
3 \cdot 0 \\
3 \cdot 6 \\
3 \cdot 8 \\
5 \cdot 7\end{array}$ & $\begin{array}{l}\overline{2 \cdot 5} \\
\overline{3 \cdot 7} \\
3 \cdot 5 \\
6 \cdot 0\end{array}$ \\
\hline
\end{tabular}

INTRAVENOUS DOSE OF PSP AND ITS URINARY EXCRETION. The relationship between the intravenous dose of PSP and its urinary excretion was studied to determine whether rate limitation of excretion observed after intratracheal injection occurred in the kidney.

Intravenous doses of $0.5,1.0,1.5$, and $3.0 \mathrm{mg}$ respectively of PSP dissolved in $4 \mathrm{ml}$ of $0.9 \%$ saline were given to subject J.M. weekly, and the urinary PSP in the first hour after the dose was measured. As shown in Fig. 1, there was a linear relationship between the intravenous dose and the amount of PSP in the urine in the first hour after the dose. This experiment was repeated in J.M. with similar findings, indicating that biliary excretion of PSP is constant under the same experimental conditions. Similar results have recently been observed in six normal subjects (Williams and Maddocks, 1975). This result shows

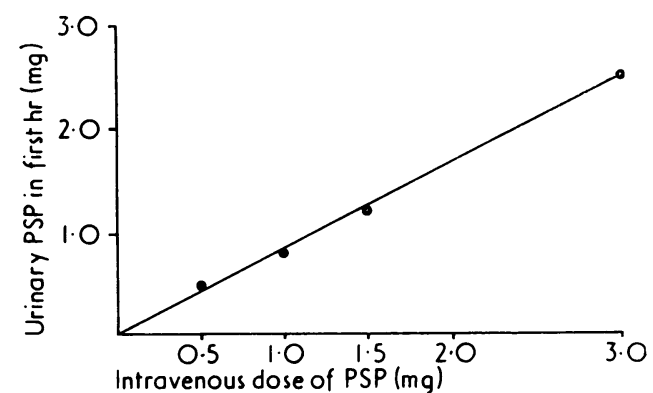

FIG. 1. Relationship between intravenous dose ( $m$ and urinary excretion $(\mathrm{mg})$ of PSP in $1 \mathrm{hr}$ in subjęt J.M.

that the rate limitation of PSP elimination observed after intratracheal dosage is not a renal effect and suggests that it occurs in the lung.

EFFECT OF p-AMINOHIPPURATE ON PSP ABSORPTIOA One possible mechanism for rate limitation of PSP absorption is the presence of an active tranछ port mechanism for organic acids in the lun Such a mechanism would be expected to show competitive inhibition of PSP absorption by p-aminohippurate as occurs in the kidney, braim and eye (Schanker, 1962). The effect of intra tracheal p-aminohippurate on PSP absorption was therefore studied.

By intratracheal injection $18 \mathrm{mg}$ of PSP (3 r of PSP solution $+2 \mathrm{ml}$ of water) was given to subject J.M., and its cumulative weight w茨 measured in the urine after $0.5,1$, and 2 hours. week later $18 \mathrm{mg}$ of PSP together with $100 \mathrm{mg}$ of sodium p-aminohippurate (volume of dose made. up to $5 \mathrm{ml}$ with water) was given by intratrache injection and the urinary excretion of PSP was measured as before. This experiment was peb formed twice. The results are shown in Table $\bar{P}$. p-Aminohippurate did not reduce the absorption of PSP from the lung, rather it resulted in slight increase during the first 0.5 hour. Tye reason for this effect is not known.

T A B L E I I

CUMULATIVE WEIGHT (mg) OF PSP EXCRETED IN THE URINE OF SUBJECT J.M. AFTER INTRATR ACHEAL $Q$ INJECTION OF (a) PSP $18 \mathrm{mg}$, AND (b) PSP $18 \mathrm{mg}+$ SODIUGA

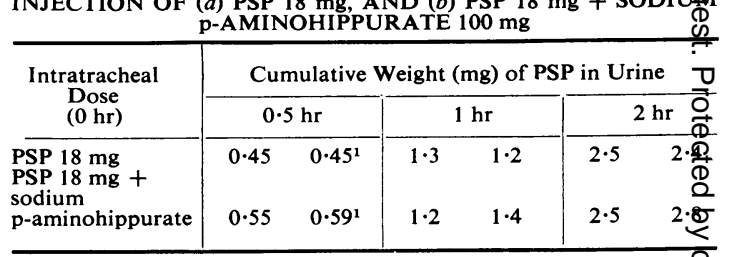

${ }^{1}$ Repeat experiment. 
EFFECT OF SALINE ON PSP ABSORPTION Since the PSP doses used in the first experiment contained differing concentrations of saline, it was thought possible that the osmotic effects of the solution might influence the rate of PSP absorption from the lung. Accordingly, the pulmonary absorption of $6 \mathrm{mg}$ of PSP in $0.9 \%$ saline was compared with the same dose in $0.18 \%$ saline. Two subjects received an intratracheal injection of PSP in $0.9 \%$ saline and also in $0.18 \%$ saline; to four subjects it was given in $0.9 \%$ saline and to the other three subjects in $0.18 \%$ saline.

As shown in Table III, the mean weight of PSP excreted in the urine in the first hour was three times greater when it was given in $0.18 \%$ saline $(1.2 \pm 0.32 \mathrm{mg})$ compared with the same dose in $0.9 \%$ saline $(0.41 \pm 0.09 \mathrm{mg})$. The difference between the means was statistically significant $(\mathbf{P}<0.001)$.

\section{T A B L E I I I}

COMPARISON OF WEIGHT (mg) OF PSP EXCRETED IN URINE IN 1 HR AFTER INTRATRACHEAL INJECTION OF (a) PSP $6 \mathrm{mg}$ IN $0.9 \%$ SALINE (6 SUBJECTS), AND (b) PSP $6 \mathrm{mg}$ IN $0 \cdot 18 \%$ SALINE (5 SUBJECTS)

\begin{tabular}{|c|c|c|c|c|}
\hline \multirow[b]{2}{*}{ Subject } & \multirow{2}{*}{$\begin{array}{c}\text { Age } \\
(\mathrm{yr})\end{array}$} & \multirow{2}{*}{ Sex } & \multicolumn{2}{|c|}{ PSP excreted in Urine in $1 \mathrm{hr}(\mathrm{mg})$} \\
\hline & & & $0.9 \%$ saline & $0 \cdot 18 \%$ saline \\
\hline $\begin{array}{l}\text { J.M. } \\
\text { D.T. } \\
\text { C.E. } \\
\text { N.H. } \\
\text { N.N. } \\
\text { A.I. } \\
\text { D.G. } \\
\text { D.D. } \\
\text { A.S. }\end{array}$ & $\begin{array}{c}28 \\
25 \\
19 \\
27 \\
30 \\
24 \\
27 \\
33 \\
25 \\
\text { Mean } \\
\text { ( } \pm \text { SD) }\end{array}$ & $\begin{array}{l}\mathbf{M} \\
\mathbf{F} \\
\mathbf{F} \\
\mathbf{M} \\
\mathbf{M} \\
\mathbf{M} \\
\mathbf{M} \\
\mathbf{F} \\
\mathbf{F}\end{array}$ & $\begin{array}{l}0.38 \\
0.50 \\
0.45 \\
0.52 \\
0.29 \\
0.33 \\
= \\
- \\
0.41 \pm 0.09\end{array}$ & $\begin{array}{l}1.6 \\
1.4 \\
= \\
\overline{1} \\
1.0 \\
1.2 \\
0.8 \\
1.2 \pm 0.32\end{array}$ \\
\hline
\end{tabular}

Comparison between groups $\begin{aligned} & t=5.02 \\ & \mathrm{p}<0.001\end{aligned}$

INTRATRACHEAL DOSE OF PSP (IN ISOTONIC SALINE) AND ITS URINARY EXCRETION The relationship between the intratracheal dose and urinary excretion of PSP was again studied in subject J.M. In this experiment doses of 3,6 , and $30 \mathrm{mg}$ of PSP were each prepared in $0.9 \%$ saline so that the tonicity of each solution was constant. The results are shown in Figure 2. PSP excretion in the urine during the first 0.5 hour after the dose was directly proportional to the dose. The same relationship held when the total PSP excreted during the first one hour and two hours was plotted against the intratracheal dose.

\section{DISCUSSION}

When the saline concentration of each dose was kept constant the pulmonary absorption of PSP

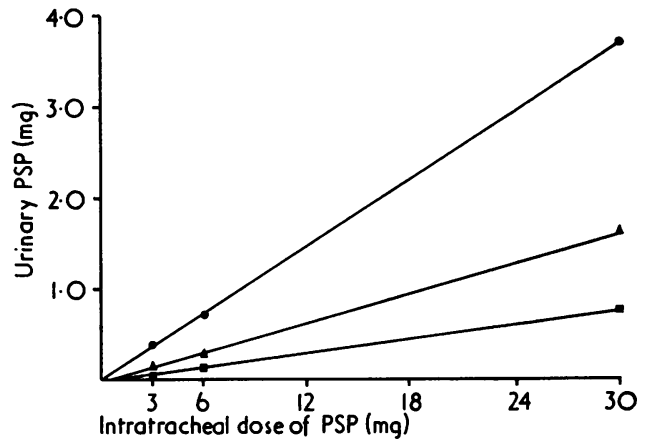

FIG. 2. Relationship between intratracheal dose ( $m g$ ) of PSP in $0.9 \%$ (isotonic) saline and its total urinary excretion ( $m g$ ) $0.5 \mathrm{hr}$ ( $\mathbf{\square}-\mathbf{\square}), 1 \mathrm{hr}(\mathbf{\Delta}-\mathbf{\Delta})$, and $2 \mathrm{hr}\left(\mathrm{O}_{-}\right)$after the dose.

was found to be directly proportional to the dose. Also, intratracheal p-aminohippurate did not reduce PSP absorption from the lung. Both these observations suggest that pulmonary absorption of PSP occurs by passive diffusion. Similar results were obtained for pulmonary absorption of ampicillin in man (Maddocks, 1974) and organic acids in the rat (Enna and Schanker, 1969). It is possible that the intratracheal lignocaine used in this study might interfere with active absorption of PSP from the lung. There is no direct evidence to exclude this effect at present. However, Eriksson and Granberg (1965), in their studies on the renal effects of lignocaine in man, found no evidence that it blocked the tubular mechanism for organic acids which actively transports both PSP and p-aminohippurate. They found no impairment of p-aminohippurate or inulin clearance even when large doses of lignocaine were given together with p-aminohippurate intravenously. The suggestion by May and Delves (1965) that there might be an active transport mechanism for ampicillin in the bronchus similar to that for organic acids in the kidney, liver (Sperber, 1959), choroid plexus (Pappenheimer, Heisey, and Jordan, 1961), and ciliary body (Becker, 1960) has not been confirmed. Viable human bronchial slices do not accumulate ampicillin (Maddocks, 1975) or p-aminohippurate (Maddocks, 1973) so it is more likely that these drugs cross the bronchial mucosa by passive diffusion.

The more rapid absorption of PSP from 0.18\% (hypotonic) saline than from $0.9 \%$ (isotonic) saline found in this study might be due to pulmonary absorption of water. In fresh water drowning, water is known to be rapidly absorbed from the human lung (Moritz, 1944), and Qualls, Curtis, 
and Meneely (1953) showed that water was very rapidly absorbed from the canine lung with a half-time of 3.8 minutes. Absorption of water from a hypotonic PSP solution would tend to increase the concentration of dye in the lung so that its absorption increases. Another possible factor that might increase the rate of PSP absorption from hypotonic solutions is 'solvent drag'. This occurs when water is absorbed through membrane 'pores' and drags with it hydrophilic molecules so that they cross the membrane faster than can be explained by diffusion alone. Thus water absorption increases the rate of PSP absorption from the canine jejunum (Tidball and Peterson, 1961) and urea absorption from the rat jejunum (Ochsenfahrt and Winne, 1973).

Pulmonary absorption of PSP in this study was found to be much greater than in published results for its gastrointestinal absorption in man. One hour after an oral dose of $30 \mathrm{mg}$ to four normal subjects, the mean urinary excretion of PSP was $0.23 \mathrm{mg}$ (McCleod et al., 1968), whereas with the same dose given by intratracheal injection to two subjects in this study the result was $1.8 \mathrm{mg}$. Enna and Schanker (1969) reported similar results for inulin (mol. wt 5000). Although not absorbed from the gut, it is significantly absorbed from the lung in the rat. Possibly the lungs have a greater permeability than the gastro-intestinal tract, although other factors such as surface area of the membrane and the effect of secretions on absorption of substances have also to be considered.

I am indebted to the late Professor J. Robert May for his helpful advice and to the volunteers who took part in these studies. The Chest and Heart Foundation provided financial support.

\section{REFERENCES}

Abramson, H. A., Reiter, C., Gettner, H. H., and Sklarofsky, B. (1949). Aerosols 1. The urinary excretion of inhaled phenolsulfonphthalein mists. Annals of Allergy, 7, 761.

Becker, B. (1960). The transport of organic anions by the rabbit eye. American Journal of Ophthalmology, 50, 862.

Enna, S. J. and Schanker, L. S. (1969). Drug absorption from the lung. Federation Proceedings, 28, 359.
Eriksson, E. and Granberg, P. (1965). Studies on the renal excretion of citanest and xylocaine. $A c t$ Anaesthesiologica Scandinavica, 9, Supplemef 16, pp. 79-85.

McCleod, G. M., French, A. B., Good, C. J., an Wright, F. S. (1968). Gastrointestinal absorption and biliary excretion of phenolsulfonphthale (phenol red) in man. Journal of Laboratory and Clinical Medicine, 71, 192.

Maddocks, J. L. (1973). Aspects of the chemotherap $\vec{y}$ of chronic bronchitis. M.D. thesis, University London.

(1975). Absorption of ampicillin from the humat lung. Thorax, 30, 68.

May, J. R. and Delves, D. M. (1965). Treatment $\dot{\phi} \beta$ chronic bronchitis with ampicillin: some pharmis cological observations, Lancet, 1, 929.

Moritz, A. R. (1944). Chemical methods for the de termination of death by drowning. Physiological Reviews, 24, 70.

Ochsenfahrt, H. and Winne, D. (1973). The contr菏 bution of solvent drag to the intestinal absorption of tritiated water and urea from the jejunum of the rat. Naunyn-Schmiedeberg's Archives of Pharmacology, 279, 133.

Pappenheimer, J. R., Heisey, S. R., and Jordan, E. E. (1961). Active transport of diodrast and phenow sulfonphthalein from cerebrospinal fluid to bloof American Journal of Physiology, 200, 1.

Qualls, G., Curtis, H. J., and Meneely, G. R. (1953 Rate of uptake of fluid from lung measured with radioisotopes; comparison of rapid rate for wate with slower rate for saline. American Journal $\vec{A}$ Physiology, 172, 221.

Schanker, L. S. (1962). Passage of drugs across body membranes. Pharmacological Reviews, 14, 50

- - (1972). Drug absorption. In Fundamentals of Drug Metabolism and Disposition, edited B. N. La Du, H. G. Mandel, and E. L. Way p. 39. Williams and Wilkins, Baltimore.

Sperber, I. (1959). Secretion of organic anions in the formation of urine and bile. Pharmacologico Reviews, 11, 109.

Tidball, C. S. and Peterson, K. K. (1961). Changes 皿 intestinal net water movements and phenolsuits phonphthalein absorption produced by ethylened aminetetraacetic acid. Physiologist, 4, 121.

Williams, G. T. and Maddocks, J. L. (1975). The effect of water on the absorption of drugs fron the human gastro-intestinal tract (in preparation.

Requests for reprints to: Dr. J. L. Maddocks, KRUథ Institute of Renal Disease, Royal Infirmary, Cardiff? 